\title{
Regeneration of lesioned corticospinal tract fibers in the adult rat spinal cord under experimental conditions
}

\author{
Martin E Schwab and Christian Brösamle \\ Brain Research Institute, University of Zurich, August Forel-Str. 1, 8029 Zurich, Switzerland
}

\begin{abstract}
The absence of fiber regrowth in the injured spinal cord and brain is influenced by several different factors and mechanisms. Among these are factors which inhibit neurite growth which are found on the surface of oligodendrocytes and central myelin. Their neutralization by a specific antibody allowed regeneration of transected corticospinal tract fibers in the adult rat spinal cord. Using a recently introduced novel neuroanatomical tracer, biotin-dextran-amine, we demonstrate the extensive regenerative sprouting of lesioned corticospinal fibers in the lesioned adult spinal cord. In the presence of the antibody against the myelin-associated neurite growth inhibitors, some of these fibers grew over remaining tissue bridges into the caudal spinal cord. They branched extensively in the lumbar spinal cord segments. These branches were decorated with synapse-like boutons. This neuroanatomical configuration probably contributes importantly to the functional recovery observed earlier in these antibody-treated animals.
\end{abstract}

Keywords: axon growth; neurotrophic factors; myelin; paraplegia

\section{Introduction}

The irreversibility of the long-term functional deficits resulting from spinal cord or brain lesions is largely due to the absence of regeneration of the lesioned axons. The cell biological reasons for this apparent inability of CNS fiber tracts to regenerate have recently become a focus of interest for many research laboratories. Due to an enormous increase in our knowledge of the mechanisms regulating fiber growth during nervous system development ${ }^{1}$ and due to the availability of powerful new techniques (biochemistry, molecular biology, cell and tissue culture techniques, modern neuroanatomical tracing methods) important insights have been gained which have changed many of the traditional views. In this article we briefly review the present state of knowledge with regard to fiber tract regeneration in the adult spinal cord (for an extensive review $\mathrm{see}^{2}$ ). We focus in particular on the work from our own laboratory, and we show new evidences for regenerative sprouting and fiber growth using a novel, high resolution neuroanatomical tracer.

\section{Adult nerve cells can reactivate a fiber growth program following lesions}

Early neuroanatomical as well as recent biochemical data show that neurons of the adult spinal cord or brain can re-enter a fiber growth state following an axonal lesion. ${ }^{2,3}$ In an extensive series of experiments

Correspondence: ME Schwab using transplants of peripheral nerves into the adult spinal cord or brain abundant fiber ingrowth from CNS neurons into these transplants was shown. ${ }^{4-6}$ These regenerating axons originate from projection neurons or from interneurons and can grow within these transplants for up to several centimeters. Genes associated with fiber growth, in particular those for the cytoskeletal protein tubulin and the growth-associated protein GAP-43 are highly expressed in nerve cells during fiber growth in development and downregulated to low levels in the adult. Both these genes are reactivated in different types of CNS neurons following axonal lesions. ${ }^{2,7-9}$ This activation of the cellular growth program is transitory. If axons do not find a growth-permissive territory, eg a peripheral nerve transplant, growth-associated genes are downregulated, and the neurons often go into an atrophic state. If the axonal lesion is very close to the cell body, many neurons eventually die. Several of the recently discovered neurotrophic factors can rescue these lesioned neurons if applied into the CNS of experimental animals. ${ }^{10,11}$

\section{Lesioned adult axons grow sprouts in response to injury}

The formation of growth cones and growing side branches (sprouts) from lesioned axons in the adult spinal cord or brain has been observed already with the methods of classical neuroanatomy. ${ }^{3}$ This process probably reflects the above described activation of 
growth-specific genes in the cell body. In adult rats with bilateral transections of the dorsal half of the spinal cord, including both corticospinal tracts, we have shown an increase in branch density rostral to the lesion $2-3$ weeks after transection. ${ }^{12,13}$ Whereas the tracer available at that time (wheat germ agglutinin coupled to horseradish peroxidase, WGA-HRP) did not allow single fiber resolution, the introduction of a highly sensitive high resolution anterograde tracer, biotin-dextran-amine (BDA) now allows the visualization of this sprouting process in great detail. ${ }^{14}$ Spinal cords of young adult (4-6 week old) rats were transected at the midthoracic (T8) level in the dorsal half bilaterally ${ }^{12}$ and BDA was injected into the sensory motor cortex. In addition, IN-1 antibodyproducing hybridoma cells (see below) were implanted. Two weeks later the animals were fixed by transcardial perfusion, the spinal cord cut serially in the sagittal plane and processed histochemically. ${ }^{14}$ Black reaction product marks the labelled corticospinal fibers. As shown in Figure 1a the corticospinal tract (CST) approaches the lesion from rostral and sprouts extensively. Dense arborizations arising sometimes from single fibers are apposed to the interface of the debris zone, the future cavern wall.

The mechanisms inducing and regulating this regenerative sprouting are not clear at present. Due to the lesions, massive changes in the tissue surrounding the trauma area take place, including an activation of astrocytes and microglia and infiltration with inflammatory cells., ${ }^{2,15}$ Cytokines are synthesized locally, ${ }^{16-18}$ fibroblast growth factor $(\mathrm{FGF})^{19}$ and transforming factor beta (TGF-beta) ${ }^{20}$ are expressed and changes in neurotrophins and their receptors also occur. ${ }^{21,22}$ Upregulation of growth-promoting substrates and possible downregulations of growth inhibitors in this perilesion area remain to be studied in detail. ${ }^{23}$

This initial regenerative attempt of the lesioned axons is of transitory nature; sprouts and also the original axons often retract within $1-2$ months following the lesion. In the case of large lesions of the rat CST the retraction distance is $1-2 \mathrm{~mm}$ from the lesion site. ${ }^{12,24}$

\section{Scars as barriers to axon growth}

The inhibitory effect of caverns and large lesion scars has been observed early in studies on spinal cord and brain lesions. $^{3,25,26}$ The typical situation suggesting a local inhibitory interaction can also be seen in our experiments, eg in the spinal cord shown in Figure 1c. The underlying biochemical mechanisms are largely unknown. The fact that growing nerve fibers are able to penetrate even dense astrocytic scars eg in amphibian optic nerves ${ }^{27}$ or in vitro ${ }^{28}$ argues against a purely mechanical effect. Proteins and proteoglycans with growth-inhibitory actions have been described in scar areas, ${ }^{29-31}$ but their direct involvement in growth inhibition at scars in vivo has not been shown yet.
Although caverns and scars are an important aspect of CNS and in particular spinal cord lesions, the typical contusion lesions often leave peripheral tissue bridges intact, both in experimental models as well as in paraplegic patients. ${ }^{32-34}$ As shown below, regenerating axons often use these tissue bridges to circumvent the lesion site.

\section{Regenerating axons bypass the lesion but do not spontaneously elongate over long distances}

Reconstructions of lesioned spinal cords with identified tracts, eg the CST, frequently show sprouting axons growing around the lesion site on intact tissue bridges. In the animal model frequently used in our laboratory (bilateral transection of dorsal spinal cord) regenerating CST axons cross the lesion site in the ventral or ventrolateral gray or white matter (Figure 1a). ${ }^{12,13,35}$ When we measured the longest distance of regeneration in control animals (no antibody or control antibody treatments), a maximal distance of regeneration of $0.2-1.2 \mathrm{~mm}$ with very rare examples up to $1.8 \mathrm{~mm}$ were seen (adult rats). ${ }^{12,13,35}$ Similar results have been observed in different experimental models and species (mammals) (for review see ${ }^{2}$ ). This suggests that additional inhibitory factors are present in the adult spinal cord tissue which prevent the elongation and long-distance regeneration of those fibers which managed to circumvent the lesion and the scar. Potent neurite growth inhibitory activity has, indeed, been found in the myelin and the oligodendrocyte plasma membranes of the adult rat spinal cord and brain. ${ }^{36}$ The biochemical analysis has given evidence for a new, high molecular weight membrane protein (neurite growth inhibitor NI-250) which is present in rat, bovine and human CNS myelin. ${ }^{36-38}$ The factor leads to rapid collapse and paralysis of neuritic growth cones by the activation of an intracellular signal cascade. ${ }^{39}$ Antisera and in particular a monoclonal antibody (inhibitor neutralizing antibody IN-1) were shown to neutralize this myelin-associated neurite growth inhibitory activity in several cell and tissue assays. ${ }^{39,40}$

\section{Antibodies against myelin-associated neurite growth inhibitors allow long-distance regeneration of lesioned adult corticospinal axons}

In several series of experiments performed in rats neutralizing monoclonal antibodies against the myelinassociated neurite growth inhibitors described above (mAB IN-1) were applied to spinal cord lesioned animals. ${ }^{12,13,35}$ When corticospinal axons were traced from the sensory-motor cortex 2-6 weeks after the lesion, a mean of $5-10 \%$ of the CST axons were observed in the segments of the spinal cord caudal to the lesion. Regeneration distances varied from animal to animal between 2.5 and $20 \mathrm{~mm}$. Control animals (no antibodies or control antibodies against an unrelated protein (horseradish peroxidase) showed regeneration distances of $0.2-1.8 \mathrm{~mm}$. The concomitant adminis- 

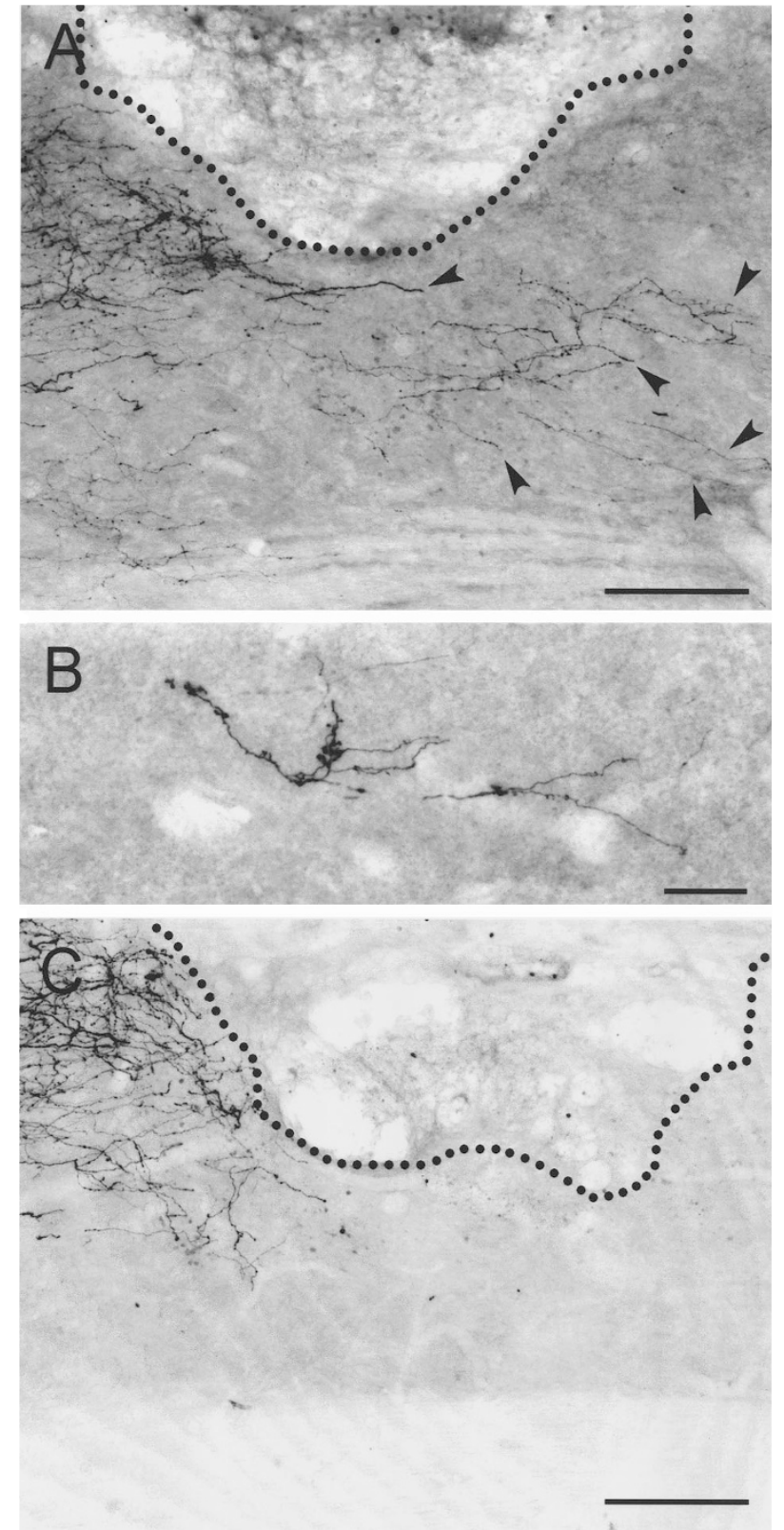

Figure 1 Parasagittal sections of the lesioned spinal cord of adult rat. Six week old rats with full bilateral transection of the corticospinal tract at T8; BDA anterograde labelling from the sensory-motor cortex; survival after lesion: 2 weeks in presence of the antibody IN-1 which neutralizes myelinassociated neurite growth inhibitors NI-35/250 $35,40,41$ (a) and (b) or a control solution (c). (a) In rats treated with the IN-1 antibody corticospinal tract fibers labelled from the sensorymotor cortex by biotin-dextran-amine (BDA) approach the injury site from the left and sprout extensively. Some of these regenerative sprouts seem to be arrested by the cavern wall. Many fibers bypass the lesion through the ventral gray matter (arrowheads). Dotted lines delineate the debris zone and future cavern resulting from the bilateral transection of the dorsal half of the spinal cord. Bar $200 \mu \mathrm{m}$. (b) Terminal arborization of a regenerated corticospinal tract fiber in the spinal gray matter $7 \mathrm{~mm}$ caudal to the lesion site. Sidebranch formation and synapse-like swellings suggest that the fiber tration of the neurotrophic factor neurotrophin 3 (NT3 ) increased the sprouting and regeneration response of the lesioned CST axons. ${ }^{35}$ Behavioural studies of these antibody-treated rats showed a very large degree of functional recovery for locomotion and for the corticospinally mediated placing response. ${ }^{41}$ In contrast, the error rate (foot falls, hindlimb) during crossing of the rats on a grid did not improve in the IN-1 antibody-treated animals. Whether the number or type of regenerating fibers were not sufficient to restore this behaviour remains to be determined. $\mathrm{mAB}$ IN-1 has also been shown to enhance the plasticity of unlesioned axons in response to local deafferentations. ${ }^{42,43}$ Thus, enhanced plasticity may also contribute, probably in addition to and in collaboration with regenerating fibers, to the improved functions observed in this behavioural study.

The detailed anatomy of regenerating fibers could only be studied recently due to the availability of the new tracer BDA (see above). The same 1-2 month old rats with partial, dorsal spinal cord transections at T8 described above were analysed for regenerating corticospinal fibers 2 weeks after the lesion. Control rats (no antibody or control antibody) did not show CST axons at distances larger than $1.5 \mathrm{~mm}$ caudal to the transection site. In contrast, many of the rats treated with $\mathrm{mAB}$ IN-1 showed long-distance regeneration; some animals had CST fibers at $10-15 \mathrm{~mm}$ caudal from the transection (lower lumbar spinal cord). Figure 1a shows CST fibers crossing the lesion site in the ventral gray matter (in rats, the CST is located in the dorsal funiculus!). Typically, these fibers show an irregular course with frequent branching and direction changes. Some fibers also grow in the ventral white matter. Regenerating CST axons reach the lower spinal segments by growing in the ventral or ventrolateral funiculus, through the gray matter, or, in about a third of the cases, by growing back into their original dorsal CST position.

A crucial question was whether these regenerated CST axons innervate spinal targets. The detailed analysis of these fibers caudal to the lesion shows that they send branches into the gray matter at various levels. These branches form terminal arbors; often equipped with typical swellings which probably correspond to synaptic boutons (Figure 1b). Integration of these regenerated axons into spinal circuits probably forms the basis for the functional recovery described above.

In Figure 1c, is the appearance of a control nonantibody treated cord for comparison.

contacts local spinal neurons. Bar $50 \mu \mathrm{m}$. (c) In rats that received a control solution, lesion-induced sprouts are occuring but they fail to elongate over long distances. No regenerating fibers bypassing the lesion site are observed. Bar $200 \mu \mathrm{m}$ 


\section{Alternative strategies: bridges and neurotrophic factors}

To circumvent the scars and their barrier effect and to approach the long-term goal of enhancing regeneration also in cases of very large spinal cord lesions, attempts were made by several laboratories to directly bridge the lesion site. Implants of embryonic tissue have been used extensively and successfully in neonatal rat and cat spinal cord lesions ${ }^{44,45}$ and (for review see ${ }^{2}$ ). In adult animals, the neuroanatomical analysis shows limited ingrowth of descending tracts into the transplants, but no real bridge function. ${ }^{44}$ Important results were also obtained with peripheral nerve transplants used as bridges in rats with complete spinal cord transections. ${ }^{4}$ Significant numbers of axons entered these bridges, a result which can be enhanced by the simultaneous administration of neurotrophic factors. ${ }^{46,47}$ In a recent study with a very sophisticated neurosurgical approach up to 18 individual peripheral nerves were transplanted from white to gray matter areas following removal of a $5 \mathrm{~mm}$ segment of lower thoracic spinal cord. ${ }^{48}$ Descending tract axons grew through these bridges and reinnervated the lumbar spinal cord. Very significant improvements in hindlimb motor coordination were observed.

Members of several families of neurotrophic factors have been described mainly in the context of studies of nervous system development. ${ }^{10,49,50}$ Infusions of some of these factors or local implantation of fibroblasts producing these factors from a transgene have been analysed in spinal cord lesions. ${ }^{51,52}$ Enhanced sprouting and growth of axons were found. Experiments using combinations of neurotrophic factors, antibodies against neurite growth inhibitors and also bridge implantations are on the way in several laboratories at present.

\section{Outlook}

The most important aspect of the current status of experimental spinal cord research is probably the fact that the dogma of the inability of CNS axons to regenerate no longer exists. Due to this, many research groups worldwide are now focussing their interest on the mechanisms involved in inducing and sustaining regeneration of lesioned axons in the spinal cord and brain. CNS lesions and regeneration have become central topics of current neurobiology, and the interaction and collaboration between the leading laboratories is intense. Combined approaches using stimulators of fiber growth as well as blockers of the endogenous neurite growth inhibitory factors, together with treatments which minimize the tissue loss and bridges which improve the conditions for regenerating fibers at the lesion site will clearly lead to regeneration of descending and ascending tract fibers in the spinal cord and to significant functional recovery in different animal models. The high similarity between mammals and man on the level of basic biological mechanisms including eg. neurotrophic factors and neurite growth inhibitors justifies the hope that these developments will also lead to novel therapeutical strategies for spinal cord injured patients in the future.

\section{Acknowledgements}

Our work is supported by the Swiss National Science Foundation (grant no. 31-45549.95), the International Research Institute for Paraplegia (Zurich), the American Paralysis Association (Springfield, New Jersey, USA) and the International Spinal Research Trust (Guildford, Surrey, England).

\section{References}

1 Goodman CS. Mechanisms and molecules that control growth cone guidance. Annu Rev Neurosci 1996; 19: 341 - 377 .

2 Schwab ME, Bartholdi D. Degeneration and regeneration of axons in the lesioned spinal cord. Physiol Rev 1996; 76: 319-370.

3 Ramon y Cajal S. Degeneration and Regeneration of the Nervous System. 1928 (Engl transl. and reprint, 1959), Hafner, New York

4 David S, Aguayo AJ. Axonal elongation into peripheral nervous system 'bridges' after central nervous system injury in adult rats. Science 1981; 214: $931-933$

5 Richardson PM, Issa VMK, Aguayo AJ. Regeneration of long spinal axons in the rat. $J$ Neurocytol 1984; 13: $165-182$

6 Keirstead SA et al. Electrophysiologic responses in hamster superior colliculus evoked by regenerating retinal axons. Science 1989; 246: $255-257$.

7 Doster SK, Lozano AM, Aguayo AJ, Willard MB. Expression of the growth-associated protein GAP-43 in adult rat retinal ganglion cells following axon injury. Neuron 1991; 6: 635-647.

8 McKerracher L, Essagian C, Aguayo AJ. Temporal changes in beta-tubulin and neurofilament mRNA levels after transection of adult rat retinal ganglion cell axons in the optic nerve. J. Neurosci 1993; 13: $2671-2626$

9 Tetzlaff W, Alexander SW, Miller FD, Bisby MA. Response of facial and rubrospinal neurons to axotomy: changes in mRNA expression for cytoskeletal proteins and GAP-43. J. Neurosci 1991; 11: $2528-2544$.

10 Lewin GR, Barde Y-A. Physiology of the neurotrophins. Annu Rev Neurosci 1996; 19: $289-317$.

11 Giehl KM, Tetzlaff W. BDNF and NT-3, but not NGF, prevent axotomy-induced death of rat corticospinal neurons in vivo. Europ J Neurosci 1996; 8: 1167-1175.

12 Schnell L, Schwab ME. Sprouting and regeneration of lesioned corticospinal tract fibers in the adult rat spinal cord. Europ $J$ Neurosci 1993; 5: 1156-1171.

13 Schnell L et al. Neurotrophin-3 enhances sprouting of corticospinal tract during development and after adult spinal cord lesion. Nature 1994; 367: 170-173.

14 Herzog A, Brösamle C. 'Semi-floating' treatment: a simple and fast method to process consecutive sections for immunohistochemistry and neuronal tracing. J Neurosci Meth 1997; (in press).

15 Dusart I, Schwab ME. Secondary cell death and the inflammatory reaction after dorsal hemisection of the rat spinal cord. Europ J Neurosci 1994; 6: $712-724$.

16 Taupin V et al. Increase in IL-6, IL-1 and TNF levels in rat brain following traumatic lesion. J Neuroimmunol 1993; 42: 177-186.

17 Kossmann T, Hans V, Imhof H-G, Trentz O, MorgantiKossmann MC. Interleukin-6 released in human cerebrospinal fluid following traumatic brain injury may trigger growth factor production in astrocytes. Brain Res 1996; 713: $143-152$.

18 Bartholdi D, Schwab ME. Expression of proinflammatory cytokine and chemokine mRNA upon experimental spinal cord injury: An in situ hybridization study; (in preparation). 
19 Koshinaga M, Sanon HR, Whittemore SR. Altered acidic and basic fibroblast growth factor expression following spinal cord injury. Exp Neurol 1993; 120: $32-48$.

20 Semple-Rowland SL et al. Analysis of TGF-betal gene expression in contused rat spinal cord using quantitative RT PCR. J Neurotrauma 1995; 12: $1003-1014$

21 Frisen $\mathbf{J}$ et al. Increased levels of trkB mRNA and trkB proteinlike immunoreactivity in the injured rat and cat spinal cord. Proc Natl Acad Sci USA 1992; 89: 11282 - 11286.

22 Frisen $\mathbf{J}$ et al. trkC expression in the injured rat spinal cord. NeuroReport 1994; 5: 349-352.

23 Frisen $\mathbf{J}$ et al. Adhesive/repulsive properties in the injured spina cord: relation to myelin phagocytosis by invading macrophages. Exp Neurol 1994; 129: $183-193$.

24 Li Y, Raisman G. Sprouts from cut corticospinal axons persist in the presence of astrocytic scarring in long-term lesions of the adult rat spinal cord. Exp Neurol 1995; 134: $102-111$

25 Puchala E, Windle WF. The possibility of structural and functional restitution after spinal cord injury. A review. Exp Neurol 1977; 55: 1 - 42 .

26 Reier PJ, Stensaas LJ, Guth L. The astrocytic scar as an impediment to regeneration in the central nervous system. In KAO CC et al, Spinal Cord Reconstruction. New York: Raven Press, 1983: $163-195$.

27 Reier PJ. Penetration of grafted astrocytic scars by regenerating optic nerve axons in Xenopus tadpoles. Brain Res 1979; 164: 61 68

28 Fawcett JW, Houdson E, Smith-Thomas L, Meyer RL. The growth of axons in three-dimensional astrocyte cultures. Dev Biol 1989; 135: $449-458$.

29 Pindzola R R, Doller C, Silver J. Putative inhibitory extracellular matrix molecules at the dorsal root entry zone of the spinal cord during development and after root and sciatic nerve lesions. Dev Biol 1993; 156: $34-48$.

30 Smith-Thomas LC et al. An inhibitor of neurite outgrowth produced by astrocytes. J Cell Sci 1994; 107: 1687- 1695.

31 McKeon RJ, Höke A, Silver J. Injury-induced proteoglycans inhibit the potential for laminin-mediated axon growth on astrocytic scars. Exp Neurol 1995; 136: $32-43$

32 Basso DM, Beattie MS, Bresnahan JC. Graded histological and locomotor outcomes after spinal cord contusion using the NYU weight-drop device versus transection. Exp Neurol 1996; 139: $244-256$.

33 Woods A, Smith ER, Gaekwad U, Kakulas BA. Establishment of a clinicopathological database for traumatic human spinal injury. Paraplegia 1991; 29: $149-155$.

34 Bunge RP et al. Observation on the Pathology of Human Spinal Cord Injury. A review and classification of 22 new cases with details from a case of chronic cord compression with extensive focal demyelination. Advanc Neurol 1993; 59: 75-89.

35 Schnell L, Schwab ME. Axonal regeneration in the rat spinal cord produced by an antibody against myelin-associated neurite growth inhibitors. Nature 1990; 343: 269-272.

36 Caroni $\mathrm{P}$, Schwab ME. Two membrane protein fractions from rat central myelin with inhibitory properties for neurite growth and fibroblast spreading. J Cell Biol 1988; 106: 1281 - 1288.
37 Spillmann AA, Amberger VR, Schwab ME. High molecular weight protein of human central nervous system myelin inhibits neurite outgrowth: an effect which can be neutralized by the monoclonal antibody IN-1. Europ J Neurosci 1997; (in press).

38 Spillmann AA, Chen MS, Schwab ME. Purification and molecular cloning of an inhibitor to CNS regeneration. Soc Neurosci 1996; 22: 734. (Abstract).

39 Bandtlow CE et al. Role of intracellular calcium in NI-35-evoked collapse of neuronal growth cones. Science 1993; 259: 80-83.

40 Caroni P, Schwab ME. Antibody against myelin-associated inhibitor of neurite growth neutralizes nonpermissive substrate properties of CNS white matter. Neuron 1988; 1: 85-96.

41 Bregman BS et al. Recovery from spinal cord injury mediated by antibodies to neurite growth inhibitors. Nature 1995; 378: $498-$ 501.

42 Schwegler G, Schwab ME, Kapfhammer JP. Increased collateral sprouting of primary afferents in the myelin-free spinal cord. $J$ Neurosci 1995; 15: 2756-2767.

43 Kapfhammer JP. Myelin-associated neurite growth inhibitors: regulators of plastic changes in neural connections in the central nervous system. Prog Brain Res 1997; (in press).

44 Bregman BS, Kunkel-Bagden E, McAtee M, O’Neill A. Extension of the critical period for developmental plasticity of the corticospinal pathway. J Comp Neurol 1989; 282: 355-370.

45 Howland DR, Bregman BC, Tessler A, Goldberger ME. Transplants enhance locomotion in neonatal kittens whose spinal cords are transected: a behavioral and anatomical study. Exp Neurol 1995; 135: $123-145$.

46 Yu XM, Guénard V, Kleitman N, Aebischer P, Bunge MB. A combination of BDNF and NT-3 promotes supraspinal axonal regeneration into Schwann cell grafts in adult rat thoracic spinal cord. Exp Neurol 1995; 134: 261 - 272

47 Chen A, Yu XM, Kleitman N, Bunge MB. Methylprednisolone administration improves axonal regeneration into Schwann cell grafts in transected adult rat thoracic spinal cord. Exp Neurol 1996; 138: $261-276$.

48 Cheng H, Cao Y, Olson L. Spinal cord repair in adult paraplegic rats: partial restoration of hind limb function. Science 1996; 273: $510-513$

49 Ip NY et al. The neurotrophins and CNTF: specificity of action towards PNS and CNS neurons. J Physiol 1991; 85: $123-130$

50 Gale NW et al. Eph receptors and ligands comprise two major specificity subclasses and are reciprocally compartmentalized during embryogenesis. Neuron 1996; 17: 9-19.

51 Oudega M, Hagg T. Nerve growth factor promotes regeneration of sensory axons into adult rat spinal cord. Exp Neurol 1996; 140: $218-229$.

52 Tuszynski $\mathrm{MH}$ et al. Nerve growth factor delivery by gene transfer induces differential outgrowth of sensory, motor, and noradrenergic neurites after adult spinal cord injury. Exp Neurol 1996; 137: 157 - 173 . 